\title{
Prevalence and Clinical Significance of Up-Sloping ST-Segment Depression in Patients With Non-ST-Segment Elevation Myocardial Infarction
}

\author{
Naoki Misumida ${ }^{\text {a } ~}{ }^{\text {, }}$, Akihiro Kobayashi ${ }^{\mathrm{a}}$, Paul Schweitzer ${ }^{\mathrm{b}}$, Yumiko Kanei ${ }^{\mathrm{b}}$
}

\begin{abstract}
Background: Up-sloping ST-segment depression has not been historically considered as representing ischemia as this electrocardiographic change can be seen in normal subjects during exercise stress testing or tachycardia. We aimed to clarify the prevalence and clinical significance of up-sloping ST-segment depression in patients with non-ST-segment elevation myocardial infarction (NSTEMI).
\end{abstract}

Methods: We performed a retrospective analysis of 330 consecutive patients with NSTEMI who underwent coronary angiography. STsegment depression $\geq 0.05 \mathrm{mV}$ in more than two contiguous leads was recorded and categorized as being up-sloping or non-up-sloping.

Results: Of 330 patients, 109 patients (33\%) had ST-segment depression; six of these patients had up-sloping ST-segment depression. All six patients with up-sloping ST-segment depression had a culprit lesion and underwent in-hospital revascularization. Three of these six patients had a culprit lesion in the left anterior descending artery; the culprit lesion in two others was in the left circumflex artery, while one patient had severe three-vessel disease. No statistically significant difference was found in the rate of in-hospital revascularization between patients with up-sloping and non-up-sloping ST-segment depression $(100 \%$ vs. $75 \%, \mathrm{P}=0.33)$.

Conclusions: Patients with up-sloping ST-segment depression had a comparable rate of in-hospital revascularization compared to those with non-up-sloping ST-segment depression, suggesting that up-sloping ST-segment depression should be recognized as a manifestation of ischemia in NSTEMI.

Keywords: Non-ST-segment elevation myocardial infarction; Upsloping ST-segment depression; Electrocardiogram

\footnotetext{
Manuscript accepted for publication August 21, 2015

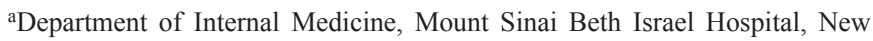
York, USA

bepartment of Cardiology, Mount Sinai Beth Israel Hospital, New York, USA ${ }^{\mathrm{c} C}$ Corresponding Author: Naoki Misumida, Department of Internal Medicine, Mount Sinai Beth Israel, 1st Avenue at 16th Street, New York, NY 10003, USA. Email: nmisumida@chpnet.org
}

doi: http://dx.doi.org/10.14740/cr422w

\section{Introduction}

The current guideline for the management of non-ST-segment elevation acute coronary syndrome includes new or presumably new ST-segment depression as one of the indications for early invasive strategy within $24 \mathrm{~h} \mathrm{[1]}$. Among several types of ST-segment depression, up-sloping ST-segment depression has not been historically considered as representing ischemia as this electrocardiographic change can be seen in normal subjects during exercise stress testing or tachycardia [2-4]. Indeed, the current guideline for myocardial infarction includes only horizontal and down-sloping ST-segment depression as a manifestation of ischemia [5]. However, up-sloping ST-segment depression has been increasingly recognized as a sign of ischemia, and up-sloping ST-segment depression with a tall positive $\mathrm{T}$ waves in precordial leads was observed in $2 \%$ cases of anterior myocardial infarction [6]. The need for guideline revision to include up-sloping ST-segment depression as a possible manifestation of ischemia has been proposed [7]. Nevertheless, the prevalence and clinical significance of upsloping ST-segment depression in non-ST-segment elevation myocardial infarction (NSTEMI) have not been fully clarified. We aimed to clarify the prevalence and clinical significance of up-sloping ST-segment depression in patients with NSTEMI.

\section{Methods}

We retrospectively reviewed all patients who underwent coronary angiography between January 2013 and June 2014 at our institution. Inclusion criteria were: 1) a troponin level greater than the 99th percentile reference value before cardiac catheterization; 2) chest pain (or anginal equivalent) or ischemic change on the electrocardiogram including ST-segment depression $(\geq 0.05 \mathrm{mV})$ or T-wave inversion $(\geq 0.1 \mathrm{mV})$ in two or more contiguous leads; and 3) absence of ST-segment elevation or new left bundle branch block on the electrocardiogram. Exclusion criteria were: 1) cardiac catheterization more than 5 days after presentation; 2) bundle branch block, electrocardiographic left ventricular hypertrophy (LVH), or ventricular paced rhythm; 3) other identifiable causes of troponin elevation; and 4) insufficient data for analysis.

The present study complied with the Declaration of Helsinki and was approved by the institutional review board. Pa- 
Table 1. Baseline Characteristics, Laboratory Data, Angiographic Findings and Clinical Outcomes

\begin{tabular}{|c|c|c|c|}
\hline & $\begin{array}{l}\text { Up-sloping ST } \\
\text { depression }(n=6)\end{array}$ & $\begin{array}{l}\text { Non-up-sloping ST } \\
\text { depression }(n=103)\end{array}$ & P value \\
\hline \multicolumn{4}{|l|}{ Baseline characteristics and risk factors } \\
\hline Age (years) & $59(49-69)$ & $67(60-78)$ & 0.24 \\
\hline Men $(\%)$ & $5(83)$ & $63(61)$ & 0.41 \\
\hline Hypertension (\%) & $4(67)$ & $80(78)$ & 0.62 \\
\hline Diabetes $(\%)$ & $1(17)$ & $38(37)$ & 0.42 \\
\hline Hyperlipidemia (\%) & $2(33)$ & $62(60)$ & 0.23 \\
\hline Previous MI (\%) & $1(17)$ & $16(16)$ & 1 \\
\hline Previous PCI (\%) & $2(33)$ & $30(29)$ & 1 \\
\hline TIMI risk score 5 - 7 & $2(33)$ & $46(45)$ & 0.69 \\
\hline \multicolumn{4}{|c|}{ Hemodynamic, laboratory data and echocardiogram findings } \\
\hline Systolic blood pressure (mm Hg) & $120(114-132)$ & $144(125-161)$ & 0.04 \\
\hline Heart rate (beats/min) & $90(78-106)$ & $81(69-95)$ & 0.51 \\
\hline Killip class $>1$ on admission $(\%)$ & $1(17)$ & $12(12)$ & 0.54 \\
\hline Peak troponin $\mathrm{I}(\mu \mathrm{g} / \mathrm{L})$ & $73.2(15.6-253)$ & $3.04(0.27-11.0)$ & 0.006 \\
\hline Left ventricular ejection fraction (\%) & $43(39-49)$ & $60(45-62)$ & 0.04 \\
\hline \multicolumn{4}{|l|}{ Angiographic findings and in-hospital events } \\
\hline Interval $^{\mathrm{a}}$ (days) & $0.4(0.3-0.8)$ & $1.0(0.3-2.1)$ & 0.22 \\
\hline Obstructive CAD (\%) & $6(100)$ & $93(90)$ & 1 \\
\hline Multi-vessel disease (\%) & $4(67)$ & $71(69)$ & 1 \\
\hline Left main/three-vessel disease (\%) & $2(33)$ & $43(42)$ & 1 \\
\hline Pre-procedural TIMI grade 0 - 1 flow (\%) & $3(50)$ & $32(31)$ & 0.38 \\
\hline Angiographic thrombus (\%) & $6(100)$ & $48(47)$ & 0.01 \\
\hline High-grade thrombus (TIMI grade 4 - 5) (\%) & $4(67)$ & $24(23)$ & 0.04 \\
\hline In-hospital revascularization (\%) & $6(100)$ & $77(75)$ & 0.33 \\
\hline In-hospital PCI (\%) & $5(83)$ & $60(58)$ & 0.4 \\
\hline In-hospital CABG (\%) & $1(17)$ & $17(17)$ & 1 \\
\hline \multicolumn{4}{|l|}{ In-hospital outcomes } \\
\hline In-hospital all-cause death (\%) & $2(33)$ & $0(0)$ & 0.003 \\
\hline In-hospital heart failure (\%) & $1(17)$ & $15(15)$ & 1 \\
\hline In-hospital cardiogenic shock (\%) & $1(17)$ & $3(3)$ & 0.22 \\
\hline Length of stay (days) & $7.6(5.2-13.5)$ & $5.8(3.0-9.4)$ & 0.22 \\
\hline
\end{tabular}

anterval from presentation to catheterization. Data are expressed as number (percentage) or median (interquartile range). CAD: coronary artery disease; MI: myocardial infarction; PCI: percutaneous coronary intervention; TIMI: thrombolysis in myocardial infarction; CABG: coronary artery bypass grafting.

tients' demographic data, risk factors and admission characteristics were obtained. Cardiac troponin I levels were measured using a second-generation VITROS ${ }^{\circledR}$ Troponin I assay (OrthoClinical Diagnostics Inc., NJ, USA). The upper limit of normal for troponin I was $0.034 \mu \mathrm{g} / \mathrm{L}$. Electrocardiograms obtained on presentation were reviewed by two independent reviewers. ST-segment shifts were measured at the J point for STsegment elevation and depression. ST-segment depression $\geq$ $0.05 \mathrm{mV}$ in more than two contiguous leads was recorded and categorized as being up-sloping or non-up-sloping (either hori- zontal or down-sloping) based on the ST-segment morphology in the lead with the most prominent ST-segment depression. Left ventricular ejection fraction was assessed by transthoracic echocardiography using either the Teichholz equation or the biplane Simpson's method.

All patients underwent cardiac catheterization within 5 days of presentation. An independent cardiologist blinded to the clinical data reviewed all coronary angiography results. Obstructive coronary artery disease (CAD) was defined as stenosis greater than or equal to $70 \%(50 \%$ in the left main 
Table 2. Clinical Data, Electrocardiographic and Angiographic Findings, and In-Hospital Outcome of the Six Patients With UpSloping ST Depression

\begin{tabular}{|c|c|c|c|c|c|c|c|c|c|c|c|}
\hline Case & Age & Sex & Symptom duration & $\begin{array}{l}\text { Leads with ST } \\
\text { depression }\end{array}$ & Interval $^{\mathbf{a}}$ & IRA & $\begin{array}{l}\text { TIMI } \\
\text { flow }\end{array}$ & $\begin{array}{l}\text { Collateral } \\
\text { grade }\end{array}$ & $\begin{array}{l}\text { No. of } \\
\text { vessels }\end{array}$ & Procedure & Outcome \\
\hline 1 & 66 & M & $45 \mathrm{~min}$ & V3-V6 & $9 \mathrm{~h}$ & LAD & 2 & 0 & $1 \mathrm{VD}$ & PCI & - \\
\hline 3 & 47 & M & 1 day & V4-V6, I, II, aVF & $34 \mathrm{~h}$ & LAD & 3 & 0 & $1 \mathrm{VD}$ & PCI & - \\
\hline 4 & 91 & M & $12 \mathrm{~h}$ & V2-V4 & $9 \mathrm{~h}$ & LCX & 0 & 0 & $3 \mathrm{VD}$ & PCI & Death \\
\hline
\end{tabular}

aInterval from presentation to catheterization. ${ }^{b}$ Intermittent crescendo chest pain. cSevere stenosis (> 95\%) in all three major coronary arteries. IRA: infarct-related artery; TIMI: thrombolysis in myocardial infarction; PCl: percutaneous coronary intervention; CABG: coronary artery bypass grafting; LAD: left anterior descending; LCX: left circumflex.

coronary artery). Angiographic findings including the number of diseased vessels, antegrade coronary flow according to the thrombolysis in myocardial infarction (TIMI) criteria, and pre-procedural thrombus grade according to TIMI study group were recorded. The infarct-related artery was determined based on the findings shown on electrocardiography, echocardiography, and coronary angiography. The primary outcome was inhospital revascularization. In addition, in-hospital mortality, presence of heart failure and cardiogenic shock, and length of hospital stay were recorded.

Data are expressed as the number (percentage) or median (interquartile range). Continuous variables were compared using the Wilcoxon rank sum test. Dichotomous variables were compared using the Chi-squared test or Fisher's exact test, as appropriate. Two-sided P-values $<0.05$ were considered statistically significant. All statistical analyses were performed with R software (version 3.0.1).

\section{Results}

Of 330 patients included in the final analysis, 109 (33\%) patients had ST-segment depression. Patients with ST-segment depression had a higher rate of in-hospital revascularization than did those without ST-segment depression (76\% vs. $63 \%$, $\mathrm{P}=0.02$ ).

Baseline characteristics and angiographic findings of patients with up-sloping and non-up-sloping ST-segment depression are summarized in Table 1. Of the 109 patients with STsegment depression, six patients had up-sloping ST-segment depression. Patients with up-sloping ST-segment depression had a higher peak troponin value and lower left ventricular ejection fraction than those with non-up-sloping ST-segment depression. All six patients with up-sloping ST-segment depression had a culprit lesion and underwent in-hospital revascularization. In-hospital mortality was higher in patients with up-sloping ST-segment depression than in those with non-upsloping ST-segment depression, and two patients with up-sloping ST-segment depression died due to cardiogenic shock and sudden death, respectively.

Clinical data, electrocardiographic and angiographic find- ings, and in-hospital outcomes of the six patients with up-sloping ST-segment depression are summarized in Table 2. The electrocardiograms obtained in case 2 and case 4 are shown in Figure 1. Three of the six patients had a culprit lesion in the left anterior descending (LAD) artery and two of the three remaining patients had a culprit lesion in the left circumflex artery. One patient had severe three-vessel disease and underwent urgent coronary artery bypass grafting.

\section{Discussion}

The current guideline for myocardial infarction does not include up-sloping ST-segment depression as a manifestation of ischemia [5]. Upsloping ST-segment depression in leads V1 to V6 with a positive symmetrical $\mathrm{T}$ wave was observed in about $2 \%$ of the patients with anterior myocardial infarction $[6,8]$. In the present study, similar electrocardiographic findings were present in two patients with a culprit lesion in proximal LAD artery (cases 1 and 2). The remaining one patient with a culprit lesion in the proximal LAD artery (case 3) presented 1 day after symptom onset and had up-sloping ST-segment depression without a tall $\mathrm{T}$ wave. Considering its association with high-risk angiographic features such as proximal lesion and high rate of impaired coronary flow, up-sloping ST-segment depression in leads V1 to V6 with a positive symmetrical T wave has been proposed to be a "STEMI equivalent" that requires immediate coronary angiography $[8,9]$. In the present study, the two patients with this electrocardiographic finding did not undergo immediate coronary angiography, highlighting a limited awareness of this high-risk nature of this finding.

Another possible cause of anterior ST-segment depression is posterior infarction. The presentation of posterior STEMI with ST-segment depression in leads V1 to V4 is well established finding [10]. In the present study, two patients with up-sloping ST-segment depression (cases 4 and 5) had a culprit lesion in the dominant left circumflex artery, consistent with posterior infarction. Upsloping ST-segment depression in precordial leads has been described in a patient with left circumflex artery occlusion [11]. It seems that up-sloping morphology of ST-segment depression occurred as a result of a 


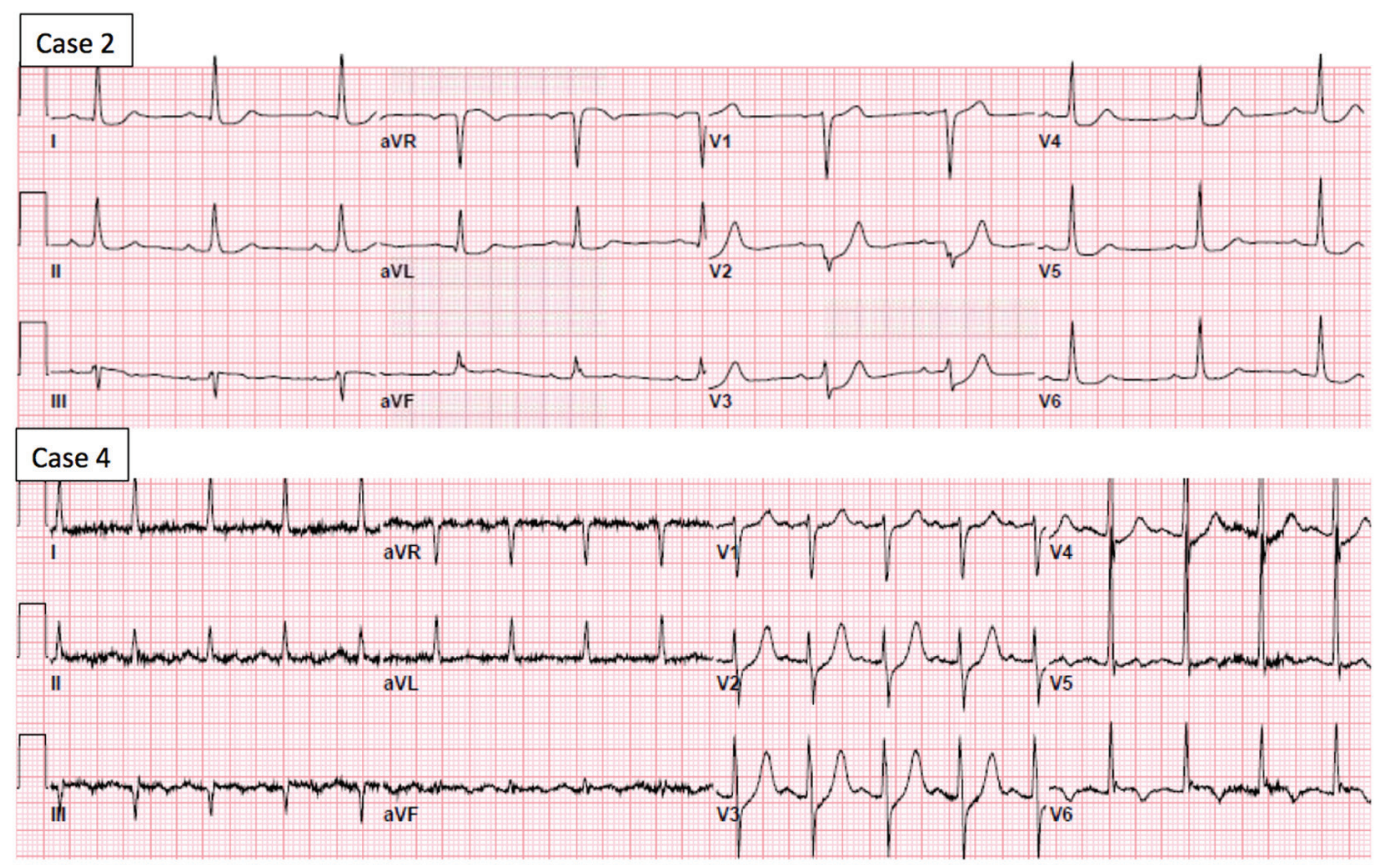

Figure 1. Electrocardiogram of case 2 shows up-sloping ST-segment depression in leads V2 and V3, and horizontal ST-depression in leads V4 to V6, I and aVL. Electrocardiogram of case 4 shows up-sloping ST-segment depression in leads V2 and V4.

mirror image of terminal T-wave inversion. ST-segment depression with positive T waves in leads V2 and V3 may represent an advanced electrocardiographic stage of posterior myocardial infarction [12]. This theory is consistent with the late presentation of the patients with left circumflex artery occlusion in the present study (cases 4 and 5).

Another possible cause of anterior ST-segment depression is multi-territory ischemia. One patient (case 6) had critical stenosis in all three major coronary arteries. Up-sloping STsegment depression secondary to severe multi-vessel disease has been reported [13]. Our study suggested that it would be prudent to recognize up-sloping ST-segment depression as a manifestation of ischemia in the setting of NSTEMI. However, it may be difficult to distinguish up-sloping ST-segment depression due to ischemia from tachycardia-induced up-sloping ST-segment depression as tachycardia itself can cause upsloping ST-segment depression and troponin elevation due to demand ischemia $[4,14]$.

The present study has several limitations. Firstly, analysis is subject to the usual constraints associated with a retrospective observational study. Second, our study cohort only included patients with NSTEMI who underwent coronary angiography, excluding patients with up-sloping ST-segment depression without troponin elevation or coronary angiography and limiting generalizability of the results.

\section{Conclusions}

Our study demonstrated that patients with up-sloping STsegment depression in the setting of NSTEMI had a compa- rable rate of in-hospital revascularization compared to those with non-up-sloping ST-segment depression, suggesting that up-sloping ST-segment depression should be recognized as a manifestation of ischemia in the setting of NSTEMI.

\section{Financial Disclosures}

None to declare.

\section{Grant Support}

None.

\section{Conflict of Interest}

None declared.

\section{References}

1. Amsterdam EA, Wenger NK, Brindis RG, Casey DE, Jr., Ganiats TG, Holmes DR, Jr., Jaffe AS, et al. 2014 AHA/ ACC Guideline for the Management of Patients with Non-ST-Elevation Acute Coronary Syndromes: a report of the American College of Cardiology/American Heart Association Task Force on Practice Guidelines. J Am Coll Cardiol. 2014;64(24):e139-228.

2. Kligfield P, Ameisen O, Okin PM. Heart rate adjustment 
of ST segment depression for improved detection of coronary artery disease. Circulation. 1989;79(2):245-255.

3. Desai MY, Crugnale S, Mondeau J, Helin K, Mannting F. Slow upsloping ST-segment depression during exercise: does it really signify a positive stress test? Am Heart J. 2002;143(3):482-487.

4. Deanfield JE, Ribiero P, Oakley K, Krikler S, Selwyn AP. Analysis of ST-segment changes in normal subjects: implications for ambulatory monitoring in angina pectoris. Am J Cardiol. 1984;54(10):1321-1325.

5. Thygesen K, Alpert JS, Jaffe AS, Simoons ML, Chaitman BR, White HD, Katus HA, et al. Third universal definition of myocardial infarction. J Am Coll Cardiol. 2012;60(16):1581-1598.

6. de Winter RJ, Verouden NJ, Wellens HJ, Wilde AA. A new ECG sign of proximal LAD occlusion. N Engl J Med. 2008;359(19):2071-2073.

7. Birnbaum I, Birnbaum Y. High-risk ECG patterns in ACS--need for guideline revision. J Electrocardiol. 2013;46(6):535-539.

8. Verouden NJ, Koch KT, Peters RJ, Henriques JP, Baan J, van der Schaaf RJ, Vis MM, et al. Persistent precordial "hyperacute" T-waves signify proximal left anterior descending artery occlusion. Heart. 2009;95(20):1701-1706.

9. Lawner BJ, Nable JV, Mattu A. Novel patterns of ischemia and STEMI equivalents. Cardiol Clin. 2012;30(4):591599.
10. O'Gara PT, Kushner FG, Ascheim DD, Casey DE, Jr., Chung MK, de Lemos JA, Ettinger SM, et al. 2013 ACCF/ AHA guideline for the management of ST-elevation myocardial infarction: executive summary: a report of the American College of Cardiology Foundation/American Heart Association Task Force on Practice Guidelines: developed in collaboration with the American College of Emergency Physicians and Society for Cardiovascular Angiography and Interventions. Catheter Cardiovasc Interv. 2013;82(1):E1-27.

11. Birnbaum Y, Bayes de Luna A, Fiol M, Nikus K, Macfarlane P, Gorgels A, Sionis A, et al. Common pitfalls in the interpretation of electrocardiograms from patients with acute coronary syndromes with narrow QRS: a consensus report. J Electrocardiol. 2012;45(5):463-475.

12. Porter A, Vaturi M, Adler Y, Sclarovsky S, Strasberg B, Herz I, Kuzniec H, et al. Are there differences among patients with inferior acute myocardial infarction with ST depression in leads V2 and V3 and positive versus negative $\mathrm{T}$ waves in these leads on admission? Cardiology. 1998;90(4):295-298.

13. Hennings JR, Fesmire FM. A new electrocardiographic criteria for emergent reperfusion therapy. Am J Emerg Med. 2012;30(6):994-1000.

14. Agewall S, Giannitsis E, Jernberg T, Katus H. Troponin elevation in coronary vs. non-coronary disease. Eur Heart J. 2011;32(4):404-411. 